\title{
A delve into the menstrual problems in teenagers: a cross sectional study in an urban school in Kerala, India
}

\author{
Resmy C. Raveendran ${ }^{1}$, Anju Mariam Jacob ${ }^{2}$, Jisha Ismail ${ }^{1}$
}

\begin{abstract}
${ }^{1}$ Department of Obstetrics and Gynaecology, ${ }^{2}$ Department of Anaesthesiology, Government Medical College, Thrissur, Kerala, India
\end{abstract}

Received: 10 September 2016

Accepted: 05 October 2016

* Correspondence:

Dr. Resmy C. Raveendran,

E-mail: drresmy@gmail.com

Copyright: ( $\odot$ the author(s), publisher and licensee Medip Academy. This is an open-access article distributed under the terms of the Creative Commons Attribution Non-Commercial License, which permits unrestricted non-commercial use, distribution, and reproduction in any medium, provided the original work is properly cited.

\begin{abstract}
Background: Onset of menstruation (menarche) is an important milestone in the adolescent girl associated with physical, psychological and social changes. Majority of the girls experience menstrual problems during this period making it even more stressful to handle. Many factors are considered to contribute to these problems of which some may be modifiable. This study was conducted to identify the menstrual problems experienced by young school girls in an urban school in Kerala and to look at any modifiable factors.

Methods: Data was collected from girls belonging to the age group of 13-18 years from an urban private school in Kerala. A detailed semi-structured questionnaire was filled by each student who participated in the study. Information regarding age of menarche, menstrual irregularities, heavy menstrual bleeding, and dysmenorrhoea. BMI of each student was calculated.

Results: The mean age of menarche was 12.05 years. The mean weight at menarche was $40.74 \mathrm{~kg}$ (SD \pm 6.66$) .24$ girls (21.86\%) reported to have irregular menstrual cycles, 76 girls $(68.47 \%)$ had menstrual cycles coming between 2435days. 22 girls $(19.82 \%)$ had cycles between $36-45$ days. 11 girls $(9.91 \%)$ had $>45$ days duration cycles. 18 girls $(16.22 \%)$ reported prolonged menstrual flow of $>7$ days, and 2 girls $(1.8 \%)$ had scanty flow. 9 girls $(8.1 \%)$ reported heavy blood loss. 60 girls $(54.1 \%)$ reported to have moderate flow. 42 girls $(37.8 \%)$ had mild blood loss. Mild to moderate dysmenorrhoea was reported in 61 girls (54.9\%), 17 girl (15.3\%) reported severe dysmenorrhoea.

Conclusions: Menstrual disturbances still pose an important problem in the life of an adolescent. Reproductive awareness programmes should be made more accessible to the adolescents.
\end{abstract}

Keywords: Dysmenorrhoea, Menstrual irregularity, Menstrual problems, Teenagers, Urban school

\section{INTRODUCTION}

Onset of menstruation(menarche)is an important milestone in the adolescent girl which is associated with physical ,psychological and social changes. ${ }^{1}$ Majority of the girls experience menstrual problems during this period making it even more stressful to handle. ${ }^{2}$ Many factors are considered to contribute to these problems of which some are modifiable. ${ }^{3}$ Adolescent girls seek medical help commonly for menstrual irregularities, dysmenorrhoea and heavy menstrual bleeding. ${ }^{4}$ Inspite of the fact that many girls have menstrual problems only a small portion seek medical help. ${ }^{5}$ This may be due to the stigma associated with menstruation ,lack of awareness about the medical options available and false beliefs associated with it. Girls attain menarche between the age of 12-13 years. ${ }^{6}$ Age of attaining menarche is showing a declining trend around the world. ${ }^{7}$ In India, even though 
mean age of menarche is reported to be around 13-14 years, it is also showing a declining trend. ${ }^{8}$ Average menstrual cycle varies from $24-35$ days. ${ }^{9}$ Any variation from this, i.e. $<24$ days or $>35$ days is considered as irregular.

This study was conducted to identify the menstrual problems experienced by young school girls in an urban school in Thrissur, Kerala and to look at any modifiable factors.

\section{METHODS}

This was a cross sectional study in an urban private school in Thrissur district in Kerala conducted after Institutional ethical clearance. Permission from the school authorities was obtained to conduct reproductive health awareness class which was followed by the study. Documented informed consent from the parents or guardian was taken. Adolescent Health awareness class was held for all girl students between 13 and 18 years, studying in $8^{\text {th }}$ through $12^{\text {th }}$ grade. Pubertal changes during menarche, normal menstrual patterns, menstrual problems and the importance of diet and exercise were discussed. Girls who had attained menarche and whose parent or guardian had given consent to give information were included in the study. Information obtained was entered in a semi structured questionnaire which included age of menarche, weight during menarche, menstrual irregularities (delayed cycles, scanty flow, heavy and prolonged flow) and dysmenorrhoea. Height and weight of the girls were recorded and Body Mass Index was calculated from these physical parameters. Awareness and access to information regarding reproductive health (Radio, TV, Magazines, internet, health awareness classes), medical help sought for the symptoms, alleviation of symptoms if any after the visit was also noted.

Awareness class was given to around 250 students in batches of 50, among whom 111girls and their parents consented to participate in the evaluation. The data obtained from the completed questionnaire were analysed using SPSS software.

\section{RESULTS}

The data obtained from the study was as follows:

\section{Age of menarche}

The mean age of menarche was 12.05years.78 (70.27\%) girls attained menarche between 12-14 years. $30(27 \%)$ girls attained menarche at 10 and 11 years. Only 1 girl had history of precocious puberty (Figure 1).

\section{Weight during menarche}

Weight during menarche was calculated. The mean weight at menarche was $40.74 \mathrm{~kg}(\mathrm{SD} \pm 6.66$ ). This was lesser than the western standards which is $47.8 \mathrm{~kg}$ in the US. Mean weight of the girls at the time of study was $47.43 \mathrm{~kg}$. Mean height was $155.66 \mathrm{~cm} .74$ girls $(66.7 \%)$ had normal BMI. 32 girls $(28.8 \%)$ were underweight and 5 girls $(4.5 \%)$ were overweight (Figure 2).

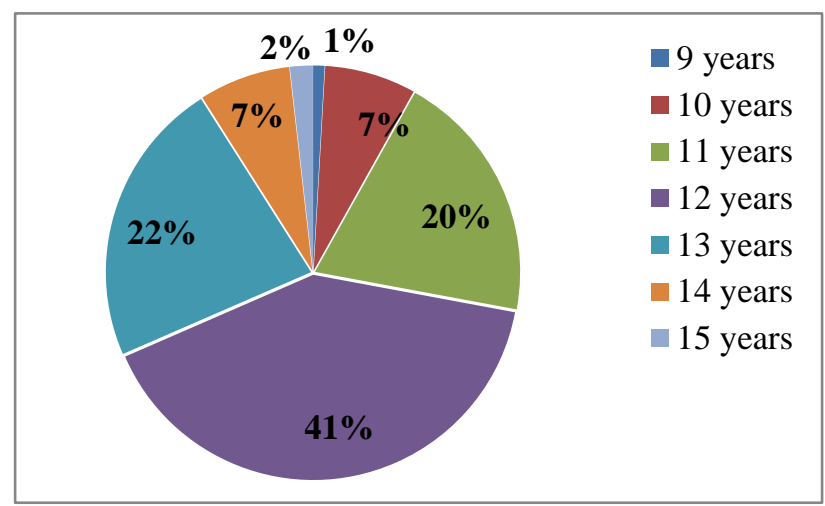

Figure 1: Distribution of age of menarche.

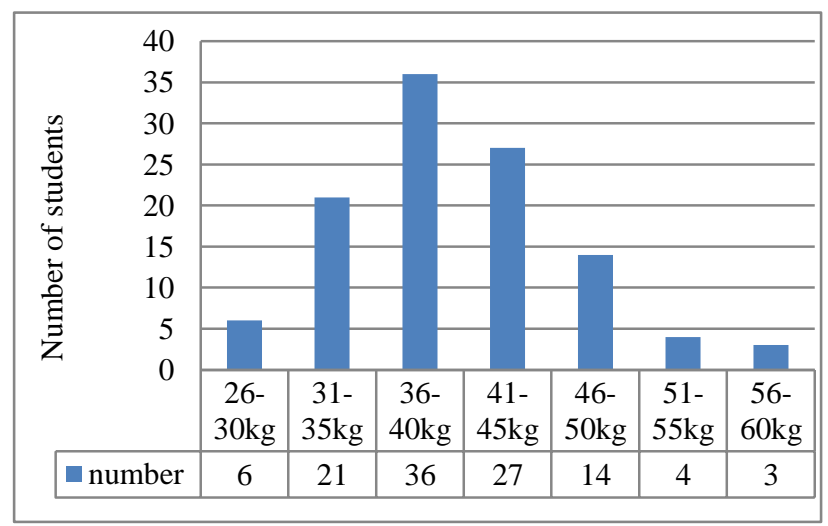

Figure 2: Weight during menarche.

\section{Menstrual irregularities}

Both regularity and frequency of the cycles were noted. Cycles that appeared regularly irrespective of the frequency were defined as regular cycles. Frequency of cycles was defined as the time elapsed between 2 consecutive cycles.

Table 1: Frequency and regularity of cycles.

\begin{tabular}{|c|c|c|c|c|c|c|}
\hline \multirow{2}{*}{$\begin{array}{l}\text { Para- } \\
\text { meters }\end{array}$} & \multicolumn{2}{|l|}{ Cycles } & \multicolumn{4}{|c|}{ Frequency of cycles } \\
\hline & Regular & Irregular & $\begin{array}{l}<24 \\
\text { days }\end{array}$ & $\begin{array}{l}24-35 \\
\text { days }\end{array}$ & $\begin{array}{l}35-45 \\
\text { days }\end{array}$ & $\begin{array}{l}>45 \\
\text { days }\end{array}$ \\
\hline $\begin{array}{l}\text { No. of } \\
\text { girls }\end{array}$ & 87 & 24 & 2 & 76 & 22 & 11 \\
\hline $\begin{array}{l}\text { Percent } \\
\text { age }\end{array}$ & $78.4 \%$ & $21.6 \%$ & $1.8 \%$ & $\begin{array}{l}68.47 \\
\%\end{array}$ & $\begin{array}{l}19.82 \\
\%\end{array}$ & $\begin{array}{l}9.91 \\
\%\end{array}$ \\
\hline
\end{tabular}

24 girls $(21.86 \%)$ reported to have irregular menstrual cycles, while $78.4 \%$ felt they had regular cycles. The frequency of cycles varied even in those who reported regular cycles. 76 girls $(68.47 \%)$ had menstrual cycles 
coming between 24-35days. 22 girls (19.82\%) had cycles between 36-45 days. 11 girls $(9.91 \%)$ had $>45$ days duration cycles. 2 girls $(1.8 \%)$ reported cycles which were $<24$ days (Table 1).

Menstrual blood loss: Duration of flow was noted as the number of days the bleeding lasted once it had started. Mild flow constituted change of 1-3 pads per day, moderate flow $4-5$ pads per day and heavy flow 6-7 pad changes per day. Any need to change pad or clothing every 1-2 hours were also grouped under heavy flow.

64 girls $(57.66 \%)$ had 4-7 days of menstrual flow, while 27girls (24.32\%) had 2-4 days of flow. 18 girls (16.22\%) reported prolonged menstrual flow of $>7$ days, and 2 girls $(1.8 \%)$ had scanty flow which was either spotting or less than 2 days (Table 2).

Table 2: Duration and amount of flow.

\begin{tabular}{|llllllll|}
\hline Parameters & Duration of flow & & \multicolumn{4}{c|}{ Amount of flow } \\
& $0-2$ days & $2-4$ days & $4-7$ days & $>7$ days & Mild- & Moderate & Heavy \\
\hline No of girls & 2 & 27 & 64 & 18 & 42 & 60 & 9 \\
\hline Percentage & $1.8 \%$ & $24.32 \%$ & $57.66 \%$ & $16.22 \%$ & $37.8 \%$ & $54.1 \%$ & $8.1 \%$ \\
\hline
\end{tabular}

9 girls $(8.1 \%)$ reported heavy blood loss quantified by the number of pad changes per day. 60 girls $(54.1 \%)$ reported to have moderate flow. 42 girls $(37.8 \%)$ had mild blood loss (Table 2).

\section{Dysmenorrhoea}

Visual analogue scale was used to quantify dysmenorrhoea. On a scale of 1 to 10 , any pain up to 5 was quantified as moderate pain and any value more than 5 was categorised as severe pain. Mild to moderate dysmenorrhoea was reported in 61 girls (54.9\%), while 17 girls $(15.3 \%)$ reported severe dysmenorrhoea. 33girls (29.7\%) suffered no pain (Table 3 ).

Table 3: Dysmenorrhoea.

\begin{tabular}{|llll|}
\hline Pain & No pain & Mild to moderate & Severe \\
\hline $\begin{array}{l}\text { Number of } \\
\text { girls }\end{array}$ & 33 & 61 & 17 \\
\hline Percentage & $29.7 \%$ & $54.9 \%$ & $15.3 \%$ \\
\hline
\end{tabular}

Table 4: Source of information of reproductive health.

\begin{tabular}{|ll|}
\hline Source & Number of girls \\
\hline Television, radio & 17 \\
\hline Magazines, books, pamphlets & 56 \\
\hline Internet & 30 \\
\hline $\begin{array}{l}\text { Health awareness class, health } \\
\text { care providers }\end{array}$ & 50 \\
\hline Relatives, friends & 74 \\
\hline
\end{tabular}

The main sources of awareness of reproductive health were from relatives, friends and printed material. Many girls received information from more than one source with 20 of them receiving information from more than 2 sources. Hence it was not possible to calculate the relative contribution of the sources of information. It was seen that a majority of the girls got reproductive health information from their relatives or friends (mostly from their mothers). Mutual discussion in the classes between friends was also cited as an important source of information. Printed material stood second as a popular source of information. Health awareness classes conducted previously in the school and visit to health care providers were also an important source (Table 4).

\section{Medical help sought}

Only 14 girls out of 78 girls $(17.9 \%)$ who suffered from dysmenorrhoea visited health care practitioners for help. Among the rest, many of them resorted to home remedies or over the counter pain relievers at some time or the other. Since more than one remedial measure was resorted to, this was not quantified. $85 \%$ (12/14 girls) of those who visited health care providers reported relief of symptoms with medication.

\section{DISCUSSION}

Attainment of menarche and a few cycles after menarche may be a turbulent period in a girl's life. The symptoms associated with this are easily treatable and in today's advanced medical world there are many ways to enjoy a "happy period" instead of dreading the unavoidable monthly ritual. Awareness regarding treatment for menstrual problem was low till recently. But in our study it was seen that $90 \%$ of the students were aware of the problems associated with menarche and subsequent period.

Age of menarche is considered to be influenced by heredity, environment, physique, physical activity and socioeconomic factors. Mean age of menarche is considered to be between 12 to 13 years in wellnourished population. ${ }^{10}$ Agarwal et al also reported a mean age of 12.6 years of menarche in affluent girls in India. ${ }^{11}$ In our study also the mean age of menarche was 
12.05 years. The mean weight at menarche noted in our study was $40.74 \mathrm{~kg}$ which was less than the mean weight at menarche of $47.8 \mathrm{~kg}$ noted in US population. ${ }^{12}$

Regularity of cycles is influenced by body mass index, hormonal and environmental factors. Menstrual cycle is commonly irregular and less frequent in the initial years of puberty because of more frequent anovulatory cycles and after a few years becomes regular as in adults. ${ }^{13}$ In our study $21.86 \%$ of girls had irregular cycles and frequency of the periods varied between 36-45 days in $19.82 \%$ and more than 45 days in $9.91 \%$ of girls. This may have been probably because many were in their initial years post menarche.

Quantifying blood loss is difficult especially in young girls as it is subjective and measurement of blood loss may not be accurate. ${ }^{14}$ Assessment of blood loss on the basis of menstrual hygiene products used may also be inaccurate because it can vary depending on the type of product (cloth, pads, cotton), socioeconomic status, disposal facility and practices of the girls. ${ }^{5,15} 6.22 \%$ girls reported prolonged menstrual blood flow of more than 7 days. $8.1 \%$ girls reported heavy blood loss quantified by the number of pads used. Since assessment of blood loss is subjective this may need further medical evaluation to know the true gravity of the situation.

Excessive blood loss can be managed by NSAIDs, balanced nutrition, vitamin and iron supplementation, antifibrinolytics and in many cases, reassurance. Health care awareness is important in most cases of menstrual disturbances which are perceived as grave by the girls, since many of the problems resolve spontaneously and often require only supportive and symptomatic management.

Dysmenorrhoea was reported in $70.2 \%$ girls of which $15.3 \%$ reported severe dysmenorrhoea. Dysmenorrhoea was found to be the most common menstrual problem among girls in a study conducted in a similar population by Nair MK et al..$^{5}$ Most cases of dysmenorrhoea are primary and spasmodic and is prostaglandin mediated. This can be effectively managed with appropriate analgesics. It was observed in our study that only $17.9 \%$ of girls who suffered from dysmenorrhoea sought medical help. Of them $85 \%$ got relief of symptoms.

Awareness of reproductive health issues is very essential in adolescent age group as it will positively affect the quality of life and have long term health implications. ${ }^{16}$ In our study the main source of awareness was found to be relatives and friends followed by printed material. Health awareness classes were reported to be effective by $50 \%$ (56) girls. This may be due to the fact that girls studying in the $8^{\text {th }}$ and $9^{\text {th }}$ grade had not been exposed to any health awareness programme previously. Studies have shown a significant improvement in knowledge on adolescent health in health education intervention. ${ }^{16}$

\section{CONCLUSION}

Menstrual disturbances still pose an important problem in the life of an adolescent. Proper knowledge about menstrual hygiene practices, nutritional education, and quantification of subjective symptoms will go a long way in improving reproductive health. Reproductive awareness programmes should be made more accessible to the adolescents.

\section{ACKNOWLEDGEMENTS}

We would like to thank the Institutional Research committee for supporting us through the study. We would also like to thank the school authorities, parents and students who willingly participated in this study.

Funding: No funding sources

Conflict of interest: None declared

Ethical approval: The study was approved by the Institutional Ethics Committee

\section{REFERENCES}

1. Karapanou O, Papadimitriou A. Determinants of menarche. Reproductive Biology and Endocrinology. 2010;8(1):1.

2. Sharma P, Malhotra C, Taneja DK, Saha R. Problems related to menstruation amongst adolescent girls. The Indian Journal of Pediatrics. 2008;75(2):125-9.

3. Gluckman PD, Hanson MA. Evolution, development and timing of puberty. Trends inEndocrinology and Metabolism. 2006;17(1):7-12.

4. Dutta R, Sengupta S. A profile of adolescent girls with gynecological problems. J Obstet Gynecol India. 2005;55:353-5.

5. Nair MK, Chacko DS, Darwin MR, Padma K, George B, Russell PS. Menstrual disorders and menstrual hygiene practices in higher secondary school girls. The Indian Journal of Pediatrics. 2012;79(1):74-8

6. World Health Organization Task Force on Adolescent Reproductive Health. World Health Organization multi- center study on menstrual and ovulatory patterns in adolescent girls. I. A multicenter cross-sectional study of menarche. J Adolesc Health Care. 1986;7:229-35.

7. Anderson SE, Must A. Interpreting the continued decline in the average age at menarche: results from two nationally representative surveys of US girls studied 10 years apart. The Journal of pediatrics. 2005;147(6):753-60.

8. Dambhare DG, Wagh SV, Dudhe JY. Age at menarche and menstrual cycle pattern among school adolescent girls in Central India. Global journal of health science. 2012;4(1):105.

9. Rev Endocr Metab Disord. Classification of menstrual bleeding disorders. MG Munro. 2012;13(4):225-34. 
10. Hillard PJ. Menstruation in adolescents: what's normal. The Medscape Journal of Medicine. 2008;10(12):295.

11. Agarwal DK, Agarwal KN, Upadhyay SK, Mittal R, Prakash R, Rai S. Physical and sexual growth pattern of affluent Indian children from 5 to 18 years of age.Indian Pediatr. 1992;29:1203-82.

12. Frisch RE. The right weight: body fat, menarche and ovulation. Baillière's clinical obstetrics and gynaecology. 1990;4(3):419-39.

13. Hickey $M$, Balen A. Menstrual disorders in adolescence: investigation and management. Hum Reprod Update. 2003;9:493-504.

14. Mansfield MJ, Emans SJ. Adolescent menstrual irregularity. J Reprod Med. 1984;29:399-410.
15. Treloar AE, Boynton RE, Behn BG, Brown BW. Variation of the human menstrual cycle through reproductive life. Int J Fertil. 1967;12:77-126.

16. Uddin MJ, Choudhury AM. Reproductive health awareness among adolescent girls in rural Bangladesh. Asia-Pacific Journal of Public Health. 2008;20(2):117-28.

Cite this article as: Raveendran RC, Jacob AM, Ismail J. A delve into the menstrual problems in teenagers: a cross sectional study in an urban school in Kerala. Int J Reprod Contracept Obstet Gynecol 2016;5:3978-82. 